www.jmscr.igmpublication.org

Impact Factor 3.79

Index Copernicus Value: 5.88

ISSN (e)-2347-176x ISSN (p) 2455-0450

crossref DOI: _http://dx.doi.org/10.18535/jmscr/v3i11.12

Journal Of Medical Science And Clinical Research

IGM Publication

An official Publication of IGM Publication

\title{
Assessment of Some Health-Related Practices and Knowledge among a Group of Egyptian Patients with Peptic Ulcer Disease
}

\author{
Authors \\ Ayman Mohammed Shamseya ${ }^{1}$, Mohammed Mohammed Shamseya ${ }^{2}$, \\ Maha Adel Salem ${ }^{3}$, Amal Samir Ahmed ${ }^{4}$, and Doaa Abdelnaby Abdelfatah ${ }^{5}$ \\ ${ }^{1}$ Department of Internal Medicine; Faculty of Medicine, University of Alexandria
}

${ }^{2}$ Dept of Clinical and Experimental Internal Medicine; Medical Research Institute, University of Alexandria

${ }^{3,4,5}$ Department of Medical-Surgical Nursing; Faculty of Nursing, University of Alexandria

Email: 1dr.ayman1977@gmail.com, ${ }^{2}$ mohamed.shamseya@yahoo.com, ${ }^{3}$ mahaadel52@yahoo.com

4amal_abdmaqsoud@yahoo.com, ${ }^{5}$ doaa.abdelwahab@yahoo.com

Corresponding Author

Dr Ayman Mohamed Abdou Shamseya

Lecturer, Department of Internal Medicine, Faculty of Medicine, University of Alexandria, Egypt

Address: 21, Elsayed Radwan St, Miami, Alexandria, Egypt

Email:dr.ayman1977@gmail.com,Phone:+201222903176

\begin{abstract}
Background: Peptic ulcer disease had a tremendous effect on morbidity and mortality until the last decades of the $20^{\text {th }}$ century, when epidemiological trends started to point to an impressive fall in its incidence due to the discovery of effective and potent acid suppressants, and of Helicobacter pylori. Despite substantial advances, this disease remains an important clinical problem, largely because of the increasingly widespread use of non-steroidal antiinflammatory drugs and poor health related practices among general populations.

The present study aimed to assess health related practices and knowledge of peptic ulcer patients.

Materials and methods: 150 adult patients diagnosed with peptic ulcer disease were selected, an Arabic healthrelated knowledge and practices structured interview schedule was the tool to collect data and was developed by the researchers based on a review of relevant literatures to assess the patients' health-related knowledge and practices related to peptic ulcer disease

The main results of this study were the following: the majority of the subjects $81.3 \%$ had poor total knowledge scores. Statistically significant differences were found between the patient's level of knowledge score and each of the followings: age; for the favor of patients who ranged between 20-30 years old, occupation; for the favor of students and office workers, residence; for the favor of residents at urban area, and education degree; for the favor of patients with high or secondary education.

Conclusions: the study concluded that doctors and nurses should provide better health education to patients, taking into account the questions and concerns of these patients.

Keywords: peptic ulcer, health-related practices, health education
\end{abstract}

\section{INTRODUCTION}

Peptic ulcer disease (PUD) is one of the most common disorders in the world, accounting for a significant portion of visits to medical providers. ${ }^{(1)}$ Over the last two decades, significant advances have been made in 
understanding the pathophysiology of PUD. ${ }^{(2)}$ In Egypt, the incidence rate of PUD is approximately 1 million people annually ${ }^{(3)}$, with 1077 deaths per year. ${ }^{(4)}$ The most common etiologies of peptic ulcer disease are Helicobacter pylori infection and non-steroidal anti-inflammatory drugs usage. Other more obscure etiologies include hypersecretory states, such as Zollinger-Ellison syndrome, G-cell hyperplasia, mastocytosis, and basophilic leukemia. ${ }^{(5)}$ Peptic ulcers were previously considered a chronic intractable disease because over $60 \%$ of ulcers recurred if their cause was not corrected.. ${ }^{(6)}$

Health-related practices are one of the most important elements in people's health and well-being which help in the prevention, treatment, and management of illness and the preservation of mental and physical wellbeing. ${ }^{(7)}$ Good health practices are defined as activities and practices performed by people to maintain a high level of wellness, improve their health, and prevent disease complications. ${ }^{(8)}$

Poor health practices and poor socioeconomic status are an important risk factor for developing PUD. ${ }^{(9)}$ Therefore, increasing attention has been paid to health promotion and disease prevention activities in the PUD because of its economic, medical, nursing and social concerns with increasing life expectancy. Also, by focusing on preventive measures to decrease morbidity and improve quality of life in patients with PUD. Therefore, health related practices and lifestyle have become important areas of concern over the last 20 years.

\section{MATERIALS AND METHODS}

Research Design: A descriptive design was used to achieve the aim of this study.

\section{Subjects:}

A convenience sample of 150 adult patients diagnosed with peptic ulcer disease according the following criteria:

1. Adults of both sexes.

2. Diagnosed with peptic ulcer (gastric or duodenal or esophageal) more than 3 months from diagnosis.

3. Aged 20 -60 years old.

4. Psychologically and physically willing to participate.

5. Patients were excluded if they had carcinoma of the stomach.

Tool of data collection: one tool was utilized for the purpose of data collection.

An Arabic Health - Related Knowledge and Practices Structured Interview Schedule was developed by the researchers based on a review of relevant literatures to assess the patients' health-related knowledge and practices related to peptic ulcer disease. It was composed of three parts:

\section{Part I: Socio-demographic characteristics and clinical data:}

\section{a) Socio-demographic data}

b) Clinical data

Part II: Peptic ulcer patients' knowledge related to peptic ulcer disease

Part III: Peptic ulcerpatients' health related practices

Data analysis: Data analysis was performed using SPSS version 18.0. Regarding scoring system, the item scores for each question were summed together; the total score was calculated by summing the scores given for its responses. The scores then transformed into score percent as the following:

Score $\%=$ (the observed score / the maximum score) $\mathrm{x} 100$

Then score $\%$ was transferred into categories as follow:

Poor: For those who had a score $\%<\mathbf{5 0 . 0 \%}$

Fair: For those who had a score \% $\mathbf{5 0 . 0} \%-<\mathbf{7 5 . 0 \%}$ 
Good score: For those who had a score $\% \geq 75 \%$.

\section{RESULTS}

\section{Patient's knowledge regarding peptic ulcer disease: (Table 1)}

More than half of the subjects $(54.0 \%$ and $56.7 \%$.) respectively didn't know the definition, and methods used for treatment of peptic ulcer disease correctly and completely.

More than one-third of the study participants (40\%) did not know the reasons related to peptic ulcer disease, and more than half of patients $(50.7 \%)$ knew the reasons related to peptic ulcer disease partially while only $(9.3 \%)$ of the studied patients who knew the reasons related to peptic ulcer completely and correctly.

Minority of the studied patients $(10.0 \%)$ knew signs and symptoms related to peptic ulcer disease completely and correctly, while the majority of them (77.3\%) knew the signs and symptoms partially correct, while $(12.7 \%)$ of them did not know any of the signs and symptoms related to peptic ulcer disease.

Minority of studied patients $(10.7 \%)$ knew risk factors related to peptic ulcer disease completely and correctly, while more than half of the studied patients $(51.3 \%)$ didn't know risk factors related to peptic ulcer disease, and (38.0\%) of them knew risk factors related to peptic ulcer disease partially correct.

More than half of the subjects (56.7\%) didn't know the methods of treatment at all, and only (6.7\%) of them knew the method of treatment completely and correctly. Also, only $(6.7 \%)$ of the studied patients knew the drugs used in treatment of peptic ulcer disease while the majority (74\%) of them partially knew the drugs used in treatment of peptic ulcer disease and (19.3\%) of the patient did not know the drugs used in the treatment.

Only7.3\% of patients who knew the complications related to peptic ulcer disease completely while more than the half $(54.7 \%)$ knew them partially, whereas $38.0 \%$ of the studied patients didn't know any of the complications.

44.0\% of the studied patients had their information about peptic ulcer disease from their own experience with the disease, while $26.0 \%$ of them had their information from another patient, the minority of them $(1.3 \%$, $3.3 \%, 5.3 \%$ and $10.7 \%$ ) had their information from nurses, friends \& relatives, doctors and reading respectively, while $9.3 \%$ of them did not have any information about peptic ulcer disease.

Overall, the majority of the studied patients $(81.3 \%)$ had a poor knowledge level, while $11.3 \%$ of them had a fair knowledge level and only $7.3 \%$ had good knowledge level.

Table 1: Distribution of the studied patients according to their knowledge regarding peptic ulcer disease:

\begin{tabular}{|c|c|c|c|c|c|c|}
\hline \multirow{3}{*}{ Knowledge items } & \multicolumn{6}{|c|}{$\begin{array}{l}\text { Adult patients with Peptic Ulcer Disease } \\
(\mathbf{n}=\mathbf{1 5 0})\end{array}$} \\
\hline & \multicolumn{2}{|c|}{$\begin{array}{l}\text { Completely } \\
\& \\
\text { Correctly Know }\end{array}$} & \multicolumn{2}{|c|}{$\begin{array}{l}\text { Partially } \\
\& \\
\text { Correctly know }\end{array}$} & \multicolumn{2}{|c|}{$\begin{array}{l}\text { Do not } \\
\text { Know/incorrect } \\
\text { answer }\end{array}$} \\
\hline & No. & $\%$ & No. & $\%$ & No. & $\%$ \\
\hline - Definition & 7 & 4.7 & 62 & 41.3 & 81 & 54.0 \\
\hline - Causes & 14 & 9.3 & 76 & 50.7 & 60 & 40.0 \\
\hline - Signs and symptoms & 15 & 10.0 & 116 & 77.3 & 19 & 12.7 \\
\hline - Risk factors & 16 & 10.7 & 57 & 38.0 & 77 & 51.3 \\
\hline - Methods of treatment & 10 & 6.7 & 55 & 36.7 & 85 & 56.7 \\
\hline - Drugs used for treatment & 10 & 6.7 & 111 & 74.0 & 29 & 19.3 \\
\hline - Complications & 11 & 7.3 & 82 & 54.7 & 57 & 38.0 \\
\hline$*$ Source of information & No. & & & $\%$ & & \\
\hline - No source & 14 & & & 9.3 & & \\
\hline
\end{tabular}




\begin{tabular}{|l|l|l|}
\hline$\bullet$ Doctor & 8 & 5.3 \\
\hline$\bullet$ Nurse & 2 & 1.3 \\
\hline$\bullet$ Friends and relatives & 5 & 3.3 \\
\hline$\bullet$ Another patient & 39 & $\mathbf{2 6 . 0}$ \\
\hline$\bullet$ Reading & 16 & 10.7 \\
\hline$\bullet$ Patient's experience with disease & 66 & $\mathbf{4 4 . 0}$ \\
\hline
\end{tabular}

* More than one answer was allowed

$\mathrm{n}=$ number of studied patients

Relationship between the scores of patients' health-related knowledge and their personal characteristics: (Table 2)

Statistically significant differences were found between the patients' health-related knowledge scores level and patients' age, where the highest score for good knowledge were among young age (20-> 30 years). In addition, statistically significant differences were detected between the patients' health-related knowledge scores and patients' occupation where, the highest score for good knowledge were for students and office workers $(60.0 \%, 14.7 \%)$, respectively. Moreover, statistically significant differences between the patients' health-related knowledge scores level and area of residence were found with the highest knowledge score for those coming from urban areas. Finally, statistically significant differences were found among the patients' health-related knowledge scores and patient educational level where, the highest knowledge score was for high and secondary education $(24.1 \%, 11.8 \%)$, respectively.

Table 2: Relationship between the patients' health-related knowledge score and their personal characteristics:

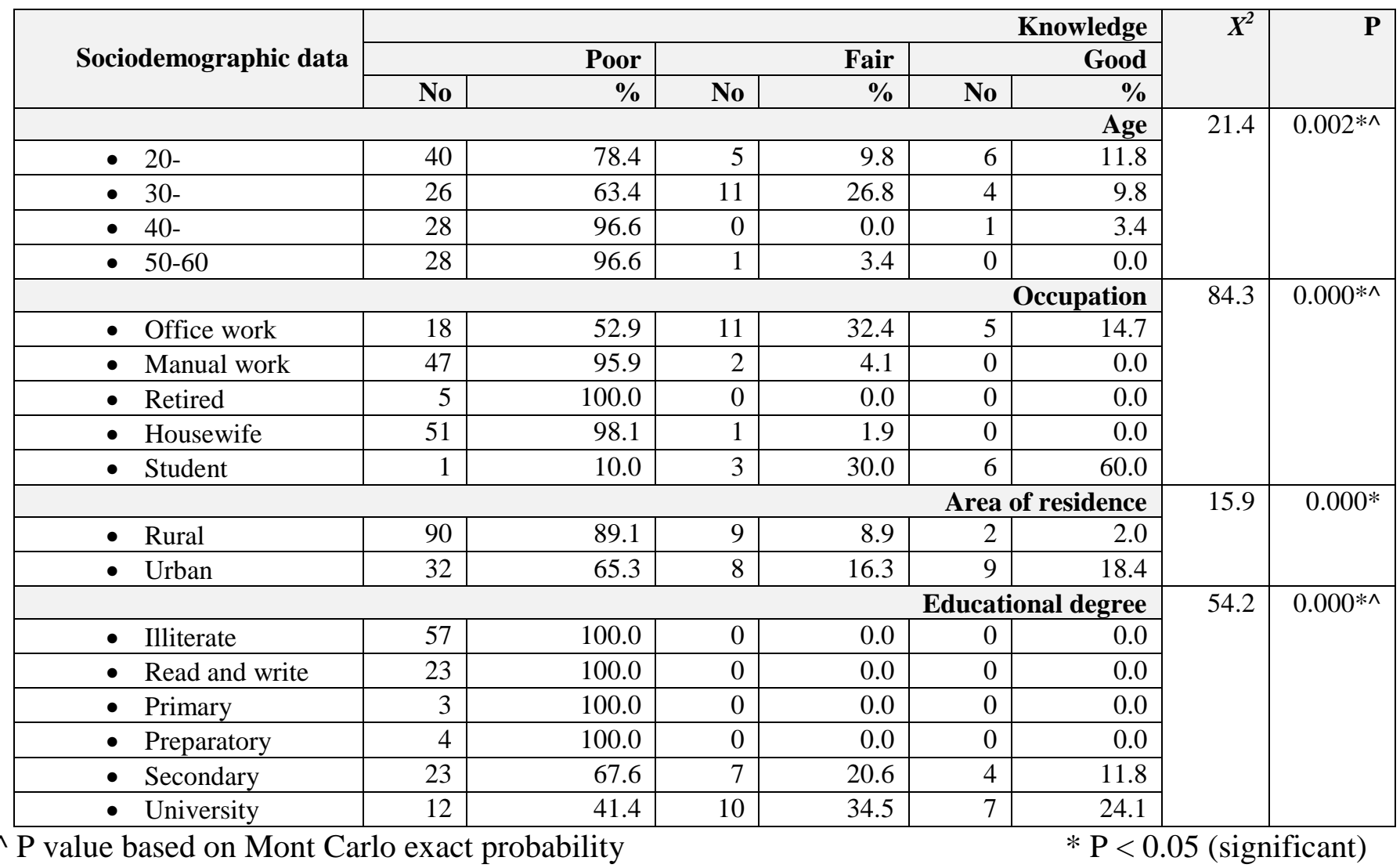


Relationship between type of ulcer and patient's age, sex, blood group and H. pylori infection: (Table 3)

The findings reveal that, statistically significant differences were found between the patients' blood group and type of ulcer in both duodenal ulcer and gastric ulcer, where, the highest percentage of those patients with gastric ulcer (43.6\%) were blood group A and the highest percentage of those patients with duodenal ulcer $(33.7 \%)$ were blood group O. Non-statistically significant differences were found between the type of ulcer and the patient's age, sex or H Pylori infection.

Table 3: Relationship between type of ulcer and patient's age, sex, blood group and H. pylori infection:

\begin{tabular}{|c|c|c|c|c|c|c|c|c|c|}
\hline & \multicolumn{8}{|c|}{ Type of ulcer } & \multirow{3}{*}{ МCP } \\
\hline & \multicolumn{2}{|c|}{ Gastric ulcer } & \multicolumn{2}{|c|}{ Duodenal ulcer } & \multicolumn{2}{|c|}{$\begin{array}{r}\text { Esophageal } \\
\text { ulcer }\end{array}$} & \multicolumn{2}{|c|}{ Don't know } & \\
\hline & $\begin{array}{r}\text { No } \\
55\end{array}$ & $\%$ & $\begin{array}{r}\text { No } \\
86\end{array}$ & $\%$ & $\begin{array}{r}\text { No } \\
2\end{array}$ & $\%$ & $\begin{array}{r}\text { No } \\
7\end{array}$ & $\%$ & \\
\hline \multicolumn{9}{|c|}{ Age in years } & \multirow{5}{*}{0.163} \\
\hline - 20- & 17 & 30.9 & 31 & 36.0 & 0 & 0.0 & 3 & 42.8 & \\
\hline - $30-$ & 15 & 27.3 & 25 & 29.1 & 0 & 0.0 & 1 & 14.4 & \\
\hline - $40-$ & 12 & 21.8 & 17 & 19.8 & 0 & 0.0 & 0 & 0.0 & \\
\hline - $50 \geq 60$ & 11 & 20 & 13 & 15.1 & 2 & 100 & 3 & 42.8 & \\
\hline & & & & & & & & nder & \multirow{3}{*}{0.206} \\
\hline - $\quad$ Male & 32 & 58.2 & 42 & 48.8 & 2 & 100 & 2 & 28.6 & \\
\hline - $\quad$ Female & 23 & 41.8 & 44 & 51.2 & 0 & 0.0 & 5 & 71.4 & \\
\hline \multicolumn{9}{|c|}{ Blood Type } & \multirow{6}{*}{$0.017^{*}$} \\
\hline - $\mathrm{A}$ & 24 & 43.6 & 13 & 15.1 & 0 & 0.0 & 0 & 0.0 & \\
\hline - $\mathrm{B}$ & 7 & 12.7 & 15 & 17.4 & 0 & 0.0 & 0 & 0.0 & \\
\hline - $\mathrm{AB}$ & 5 & 9.1 & 10 & 11.6 & 0 & 0.0 & 1 & 14.3 & \\
\hline - $\mathrm{O}$ & 10 & 18.2 & 29 & 33.7 & 1 & 50.0 & 0 & 0.0 & \\
\hline - $\quad$ Don't know & 9 & 16.4 & 19 & 22.1 & 1 & 50.0 & 6 & 85.7 & \\
\hline \multicolumn{9}{|c|}{ H pylori infection } & \multirow{3}{*}{0.641} \\
\hline - $\quad$ No/don't know & 15 & 27.3 & 27 & 31.4 & 0 & 0.0 & 3 & 42.8 & \\
\hline - $\quad$ Yes & 40 & 72.7 & 59 & 68.6 & 2 & 100 & 4 & 57.1 & \\
\hline
\end{tabular}

MCP: P value based on Mont Carlo exact probability

$* \mathrm{P}<0.05$ (significant)

\section{DISCUSSION}

In the current study, data about patients' knowledge scores regarding peptic ulcer disease proved that the highest proportion of the studied patients scored as poor health-related knowledge. This result may be related to that, high proportion of studied patients were illiterate and from rural areas or that, the majority didn't receive adequate information from health care personnel.

This finding matched completely with Lee et al, in a study conducted about peptic ulcer disease and Jamaican patient awareness on 2007, ${ }^{(10)}$ which showed that, awareness of Jamaican patients about peptic ulcer disease were inadequate and therefore, the study suggested that, there is a need for more physician education of their patients as well as public health promotion about peptic ulcer disease.

The current study illustrated that, there were statistically significant differences between the patient' healthrelated knowledge scores and patient age, occupation, area of residence and level of education. This significance was contradicted by Sonnenberg, ${ }^{(11)}$ who mentioned that, there were no significant difference between the patients' knowledge related to peptic ulcer disease and their age, sex, area of residence, and occupation.

In the present study, it was observed that there were statistically significant differences between the patient's blood group type, and type of ulcer in both duodenal and gastric ulcer. This significance was supported by Salih, ${ }^{(12)}$ who mentioned that, O blood group individuals were more susceptible to H. pylori infection and its 
symptomatic gastrointestinal complications. Also, in agreement with Kanbayet al, ${ }^{(13)}$ who mentioned that, patients with blood groups $\mathrm{A}$ and $\mathrm{O}$ were more prone to $\mathrm{H}$. pylori infection and thus to peptic ulcer disease. The effect of smoking and coffee intake on ulcer incidence was the subject of many studies with different results. Smoking is well known to have a number of adverse effects on mucosal aggressive and protective factors. ${ }^{(14)}$

Peptic ulcers are more common in smokers than in non-smokers. Cigarette smoking is positively associated with peptic ulcer pathogenesis and delayed ulcer healing. Several studies have shown that cigarette smoke and its active ingredients can cause mucosal cell death, inhibit cell renewal, decrease blood flow in the gastrointestinal mucosa, and interfere with the mucosal immune system. ${ }^{(15,16)}$

The present study shows that, the majority of studied male patients (57 out of 78 or $73 \%$ ) reported that they were smokers.

Similar findings were reported by Chen et al, who supposed a strong association between cigarette smoking \& stimulants (coffee) and prevalence of DUs, and this prevalence increase linearly with an increase in the number of cigarettes smoked, irrespective of the duration of smoking and increased with an increase in the number of cups of coffee ingested daily ${ }^{(17)}$.

On the other hand, these findings were contradicting with Mukhopadh et al, ${ }^{(14)}$ who conducted a study of smoking habits among slum dwellers and the impact on health among the population of West Bengal. The study proved that, there was a low effect of smoking on ulcer incidences.

Recommendations: the researchers recommended the following:

- Doctors and nurses should receive advanced educational programs about health-related practices of peptic ulcer disease.

- Booklets and diagnostic tools should be available and distributed to each patient with peptic ulcer disease about disease and health-related practices.

- Doctors and nurses should provide health education to patients, taking into account the questions and concerns of these patients.

- Further studying the factors involved in patient compliance and testing the effectiveness of complianceenhancing strategies.

Financial support / grants: The authors declare no financial support / grants regarding this work.

Conflict of interest: The authors declare no conflict of interest regarding this work

\section{REFERENCES}

1. Vakil N. Gastrointestinal and Liver Disease: Pathophysiology, Diagnosis, Management. $9^{\text {th }}$ ed. Philadelphia, WB Saunders. 2010; 270.

2. Theodore W. Peptic Ulcer Disease. American College of Gastroenterology 2012; 301 (1): 263-66.

3. Right Diagnosis.com, Statistics by Country for Peptic Ulcer, Health Grades, Inc, available at: http://www.rightdiagnosis.com. Retrieved on, 6/2012.

4. Wolfram Alpha Computational Engine. Wolfram Alpha knowledge base. DALY: Disability And Peptic Ulcer Disease, Adjusted Life Years, 2011, available at http://www.wolframalpha.com. Retrieved on, 5/2012.

5. Papatheodoridis G, Sougioultzis S, Archimandritis A. Effectsof Helicobacter Pylori and Nonsteroidal Anti-Inflammatory Drugs on Peptic Ulcer Disease: A Systematic Review. Journal Clinical Gastroenterology and Hepatology 2006; 4 (2): 130-42. 
6. Allahverdiyev AM, Bagirova M, Caliskan R, et al. Isolation and diagnosis of Helicobacter pylori by a new method: microcapillary culture. World J Gastroenterol 2015;21:2622-2628.

7. Green, L. W and Kreuter, M. (2002). Health Promotion Planning: An Ecological and Environmental Approach, 3rd ed. Mountain View, CA: Mayfield Publishing Co. P 234

8. Rosenstock S, Jørgensen $\mathrm{T}$ and Bonnevie O, et al .Does Helicobacter Pylori Infection Explain All Socioeconomic Differences in Peptic Ulcer Incidence? Genetic and Psychosocial Markers for Incident Peptic Ulcer Disease in A Large Cohort of Danish Adults. Scand Journal of Gastroenterology. 2004; 39(9):823-9.

9. Lee R, Loke A. Health-Promoting Behaviors and Psychosocial Well-Being of University Students in Hong Kong. Public Health Nursing 2005; 66 (5): 271-2.

10. Lee M, Soyibo K, Garro I, et al. Peptic Ulcer Disease and Jamaican Patients' Awareness of Their Disorders. West Indian Medical Journal 2007 Jun; 44 (2): 58-9.

11. Sonnenberg A. Knowledge about Causes of Peptic Ulcer Disease. Journal of Occupied Medicine 2002; 29 (1): 756-61

12. Salih M.Relationship between ABO blood group and Helicobacter Pylori Infectionin Symptomatic Patients. Clinical Expression Gastroenterology. 2011; 4: 221-6.

13. Kanbay M, Gur G, Arslan H, et al. The relationship of ABO Blood Group, Age, Gender, Smoking, and Helicobacter pyloriin Infection. Digestive Disease Science. 2005; 50(7):1214-7.

14. Mukhopadh S. Smoking Habits among Slum Dweller and the Impact on Health among the Population of West Bengal. Journal of Gastroenterology and Hepatology 2007; 10 (6): 633-8.

15. Li LF, Chan RL, Lu L, et al. Cigarette smoking and gastrointestinal diseases: the causal relationship and underlying molecular mechanisms (review). Int J Mol Med 2014;34:372-380.

16. Rantanen T, Udd M, Honkanen T, et al. Effect of omeprazole dose, nonsteroidal anti-inflammatory agents, and smoking on repair mechanisms in acute peptic ulcer bleeding. Dig Dis Sci 2014;59:26662674.

17. Chen T, Chang F, Lee S. Smoking and Male Gender Rather than CagA Protein are Associated with Increased Risk of Duodenal Ulcer in Helicobacter pylori- Infected Patients in Taiwan. Journal of Digestive Diseases and Sciences2000; 44 (2): 2076-80. 